\title{
AN ANALYSIS OF THE STRUCTURE AND THERMAL CONDUCTIVITY OF HOLLOW MICROSPHERE FILLED SYNTACTIC FOAMS
}

\author{
Rositsa PETKOVA-SLIPETS ${ }^{1,{ }^{*}, \text { Penka ZLATEVA }}{ }^{2}$ \\ ${ }^{1}$ Department of Civil Engineering, Faculty of Architecture, Varna Free University "Chernorizets \\ Hrabar", Resort Chaika, 9007 Varna, Bulgaria. \\ ${ }^{2}$ Department of Thermal Engineering, Shipbuilding Faculty, Technical University of Varna, Studentska \\ Str. 1, 9010 Varna, Bulgaria. \\ "corresponding author: rositsa.petkova@vfu.bg.
}

\section{Abstract}

The influence of types and parameters of hollow microspheres in the composition of syntactic foams on their structure and coefficient of thermal conductivity has been studied. By using structural and thermal analysis it has been found that the volume concentration and the size of the ceramic and glass hollow microspheres have a strong impact on the density and thermophysical properties of the thin syntactic foams coatings. It has been shown that the best heat insulating properties belong to syntactic foam with composition of 60 vol. \% ceramic microspheres with particle size of $1-40 \mu \mathrm{m}(k=0.029$ $\left.\mathrm{W} / \mathrm{m} \cdot \mathrm{K}, R=0.008\left(\mathrm{~m}^{2} \cdot \mathrm{K}\right) / \mathrm{W}\right)$ and with composition of $80 \mathrm{vol}$. \% glass hollow microspheres with particle size of $9-25 \mu \mathrm{m}(k=0.087 \mathrm{~W} / \mathrm{m} \cdot \mathrm{K}$, $\left.R=0.008\left(\mathrm{~m}^{2} \cdot \mathrm{K}\right) / \mathrm{W}\right)$. The results demonstrate that application of syntactic foams as thin insulating coatings is appropriate and they are an energy efficient material with number of benefits compare with the common thermal insulators.
\end{abstract}

\section{Keywords:}

Syntactic foams; Ceramic microspheres;

Glass microspheres; Infrared thermography; Thermal conductivity.

\section{Introduction}

Syntactic foams are a new and promising generation of materials, which could be used as thinlayer heat insulating coatings as well. These are usually gas-filled composite polymeric materials, where different organic binders and microspheres are used as filler, uniformly distributed in the matrix. At this stage, industrial significance have mono-component binders, which are most commonly an acrylic-based water solution, phosphate adhesive or silicon but bicomponent, epoxy resin-based ones, are also successful [1 - 7]. The closed porosity of these foams is formed not in the result of the use of gas-generating or foaming additives, but thanks to the introduction of $40-80 \%$ hollow spherical particles. The syntactic foams have a low thermal conductivity, low density and good processibility thanks to the microspheres, as well as mechanical strength and heat resistance owing to the binder [1 - 4]. The microspheres, which are used as filler, can be solid or hollow, made of glass, ceramic or polymer [2, 3, 8 - 11]. Each type has its share in achieving an optimal complex of physical-mechanical properties of the composite, and it has been found that ceramic and glass hollow microspheres appear to be the most suitable.

Substantial advantage of syntactic foams is their workability: they are easy to apply, have good adhesion to the surface and good decorative appearance. In their initial state, they are flowable compositions, which form their final structure after evaporation of the water from the solution of the matrix. Thin-layer heat insulating coatings are an innovative material that is still at the stage of development and acceptance. There is plenty of information, both scientific and industrial, but it is highly diverse in terms of their thermophysical parameters (thermal conductivity coefficient from $0.0001 \mathrm{~W} / \mathrm{m} \cdot \mathrm{K}$ to $0.2 \mathrm{~W} / \mathrm{m} \cdot \mathrm{K}$ ) and effectiveness [2, 4, 5, 12]. In view of the expected mass introduction into practice of these and similar ultrathin heat insulating coatings, it is required that they are studied more thoroughly and their thermo-technical parameters be defined more precisely. 
The main purpose of this research is to study the impact of the type and parameters of the filler used in compositions of syntactic foams used as insulating coatings on their structure and thermal conductivity coefficient. The analysis of the obtained results will help to optimize the quality of their compositions and to predict their behaviour in real conditions.

\section{Experimental}

\subsection{Materials and sample preparation}

Four compositions (SFC-1, SFC-2, SFG-1 and SFG-2) of syntactic foams based on water dispersion of an acrylic polymer with hollow microspheres of different type and quantity were studied (Table 1).

Table 1: Composition of the samples with thin heat-insulation coatings.

\begin{tabular}{|c|c|c|c|c|}
\hline Composition & Microsphere type & $\begin{array}{l}\text { Size / quantity of } \\
\text { microspheres }\end{array}$ & $\begin{array}{c}\delta^{*} \\
\mathrm{~mm}\end{array}$ & $\begin{array}{c}\rho^{\star *} \\
\mathrm{~kg} / \mathrm{m}^{3}\end{array}$ \\
\hline SFC-1 & Alumino-silicate & $1-40 \mu \mathrm{m} / 60 \%$ & $0.253 \pm 0.020$ & $315 \pm 6.2$ \\
\hline SFC-2 & Alumino-silicate & $1-40 \mu \mathrm{m} / 80 \%$ & $0.347 \pm 0.020$ & $215 \pm 6.4$ \\
\hline SFG-1 & Glass microspheres & $9-25 \mu \mathrm{m} / 80 \%$ & $0.716 \pm 0.012$ & $125 \pm 3.4$ \\
\hline SFG-2 & Glass microspheres & $20-80 \mu \mathrm{m} / 80 \%$ & $0.465 \pm 0.040$ & $165 \pm 5.1$ \\
\hline
\end{tabular}

10 pieces of each type were prepared by using of glass plate pads with length of $200 \mathrm{~mm}$, width of $200 \mathrm{~mm}$ and thickness of $8 \mathrm{~mm}$ (Fig. 1.). A coating of each composition was applied with a spray gun, in two layers. The second layer was sprayed on the first one after 6 hours of drying at room temperatures. The thickness of the coatings was measured at 144 points of a coordinate machine.

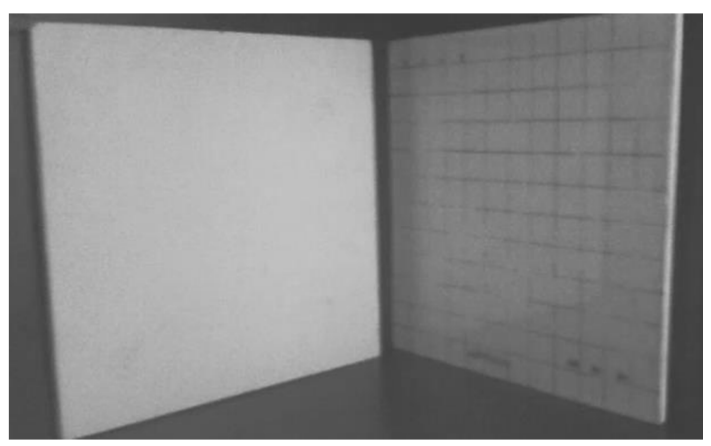

Fig.1: General view of a testing specimen.

\subsection{Equipment and research methods}

\subsubsection{Structure}

The structure of the samples was studied by a light inverted microscope METAM LV-41 and was photographed with the visualization complex TC-500. Different optical magnifications were used in conditions of a bright field with differential-interference contrast, a bright field with oblique illumination and a dark field for better visualization of the studied objects and a better highlight of the structural components. This allows the unpolished, dull, with partial light-reflective ability (only from the glass microspheres) white surface to be better observed.

\subsubsection{Thermophysical tests}

The thermophysical parameters were determined by analyzer for thermal conductivity TCi and were processed with specialized software TCi3.0. The analyzer is based on the modified transient plane source (MTPS) method.

The test consists in unilateral thermal impact from the TCi-sensor to the sample. For an integrated assessment of the heat-conducting properties of each of the tested samples with thin-layer 
coatings, were carried out 10 measurements in 10 different points. The TCi analyzer measures the thermal effusivity $e$ and the thermal conductivity coefficient $k$.

All tests were conducted by observing the methodology for work with $\mathrm{TCi}$ analyzer and the requirements of the ISO 22007-2:2015 [13]. Before each measurement, a test was carried out with Pyrex calibration material.

\subsubsection{Infrared thermography}

An infrared camera FLIR E60bx with a resolution of $320 \times 240$ pixels and lens FOL18 was used. Due to the high emission capability of the coatings (white surface and high content of reflective microspheres), work was performed at emission coefficient of 0.70 . Specialized software FLIR Tools and FLIRResearchIR was used for data processing.

Infrared photographing was carried out at the following conditions: temperature of the heat source of $65^{\circ} \mathrm{C}$; temperature of the glass plate pad of the tested samples of $45^{\circ} \mathrm{C}$; temperature of the air in the room: $15^{\circ} \mathrm{C}$.

\section{Results and discussion}

\section{1 Structural analysis of the coatings}

Fig. 2 shows the structures of the thin coatings, made by different syntactic foams compositions. All coatings have a relatively homogeneous structure with uniform distribution of the microspheres within the polymer matrix.

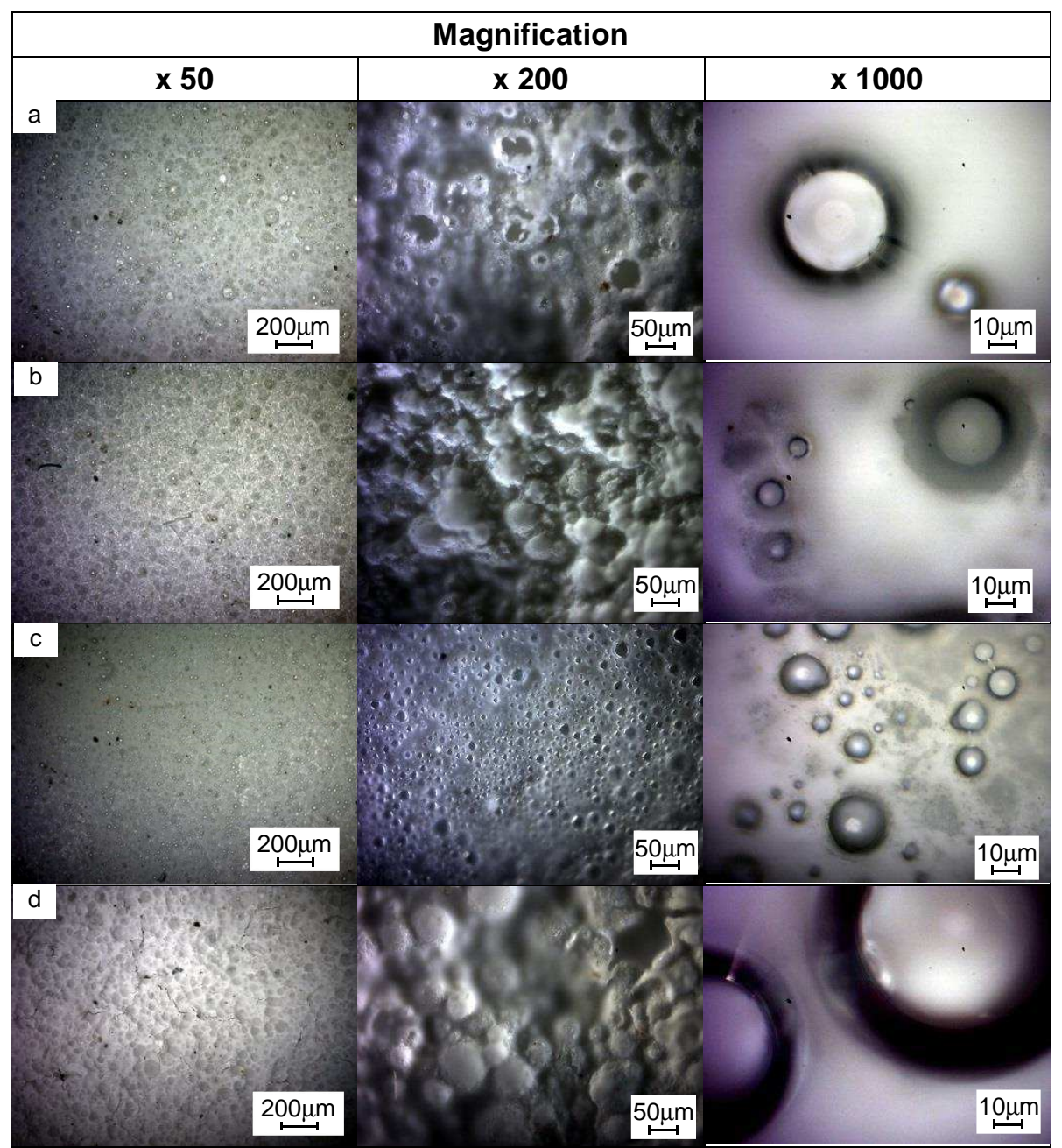

Fig. 2: Structures of the studied samples at different magnifications: a) SFC-1; b) SFC-2; c) SFG-1; d) SFG-2. 
The structures of coatings with composition SFC-1 and SFC-2, i.e. with ceramic microspheres, have a well-expressed relief on the surface. Air gaps are formed between the spheres and the matrix. The surface of the coating with composition SFG-1 has relatively good smoothness. The glass microspheres are well enveloped by the matrix without the presence of air gaps. The coating, whose composition has the largest diameter of microspheres, composition SFG-2, shows and most coarse surface with strongly-expressed relief.

The multitude of ceramic microspheres with a continuous dimensional factor within the range of 1 - $40 \mu \mathrm{m}$ (composition SFC-1) form thin layers in the structure of the coating (Fig. 2a). The hollowness of the microcapsules provides a peaceful airless inner part, which is a prerequisite for excellent heat insulating properties of the coating.

The structure of the coating with composition SFC-2 is non-compact, which is proved by its rough surface (Fig. 2b). Due to the doubled size of the specific area of the microspheres, the lather remains unenveloped by the matrix, because the quantity of the binder does not change.

The glass fine hollow microspheres (size $9-25 \mu \mathrm{m}$, composition SFG-1) contribute to their better compactness and, correspondingly, to thinner layers of the matrix substance between them. The microcapsules are well enveloped by the matrix. As a result, "thick" layers are formed with a relatively smooth surface (Fig. 2 c), but also with the lowest density (Table 1).

The great number of microspheres in composition SFG-2 and their coarse granularity $(20-90$ $\mu \mathrm{m})$ results in formation of a non-compact and rough structure with strongly-expressed relief of the surface (Fig. 2d). Similarly to composition SFC-2, the microcapsules are not well enveloped by the binder and air gaps are visible between them and the matrix.

\section{2 Influence of syntactic foams composition on coating's thermophysical properties}

Table 2 presents the results experimentally obtained from testing the samples on a TCi analyzer by the method of short-term heat source. The relative standard deviation (RSD) for all measurements is less than $1 \%$.

Table 2: Results for the thermal characteristics of the tested samples.

\begin{tabular}{|c|c|c|c|c|}
\hline \multirow{2}{*}{ Composition } & $k_{e q}$ & $\mathrm{RSD}$ & $k$ & $R$ \\
\cline { 2 - 5 } & $\mathrm{W} /(\mathrm{m} \cdot \mathrm{K})$ & $\%$ & $\mathrm{~W} /(\mathrm{m} \cdot \mathrm{K})$ & $\left(\mathrm{m}^{2} \cdot \mathrm{K}\right) / \mathrm{W}$ \\
\hline SFC-1 & 0.395 & 0.7 & 0.029 & 0.008 \\
\hline SFC-2 & 0.722 & 0.5 & 0.116 & 0.002 \\
\hline SFG-1 & 0.421 & 0.6 & 0.087 & 0.008 \\
\hline SFG-2 & 0.818 & 0.5 & 0.205 & 0.002 \\
\hline
\end{tabular}

The equivalent thermal conductivity coefficient keq was measured for the system glass plate pad - thin syntactic foam coating. The thermal conductivity coefficient of the coating $k$ was calculated by the methodology developed and described in [14]. The heat resistance was also calculated for all compositions of the tested thin coatings.

The lowest value of thermal conductivity coefficient belongs to the coating with composition SFC-1 $(k=0.029 \mathrm{~W} / \mathrm{m} \cdot \mathrm{K})$, i.e. the ceramic microspheres in a volumetric concentration of $60 \%$ and size $1-40 \mu \mathrm{m}$ enable the best heat insulating properties. The equivalent coefficient $\mathrm{keq}$ is almost 3 times lower than the thermal conductivity coefficient of the glass base $\left(k_{\text {glass }}=1.18 \mathrm{~W} / \mathrm{m} \cdot \mathrm{K},[14]\right)$ and nearly 10 times lower than that of the composite matrix $\left(k_{\text {acrylic }}=0.2 \mathrm{~W} / \mathrm{m} \cdot \mathrm{K},[15]\right)$.

By increasing the concentration of the ceramic microspheres in the composition of the composite (composition SFC-2), the thermal conductivity coefficient of coating $k$ and the equivalent thermal conductivity coefficient keq increase. However, the equivalent coefficient keq is nearly 1.5 times lower than the thermal conductivity coefficient of the glass plate and nearly 1.7 times lower than that of the matrix.

The coating with composition SFG-1 has a very low thermal conductivity coefficient $(k=0.089$ $\mathrm{W} / \mathrm{m} \cdot \mathrm{K})$, but it is higher than that of the coating with composition SFC-1 $(k=0.029 \mathrm{~W} / \mathrm{m} \cdot \mathrm{K})$. It should be noted, that the finer glass microspheres have a smaller volume of the gas phase closed within them in comparison with the ceramic microspheres, which have a larger volume share of hollowness. The equivalent coefficient keq is by $35 \%$ lower than the thermal conductivity coefficient of the glass 
plate, and the thermal conductivity coefficient of the coating $k$ by $45 \%$ lower than the thermal conductivity coefficient of the matrix.

Composition SFG-2 shows the highest thermal conductivity coefficient $(k=0.205 \mathrm{~W} / \mathrm{m} . \mathrm{K})$ in comparison with the other studied compositions. The equivalent coefficient $k e q$ is about 1.4 times lower than the thermal conductivity coefficient of the glass plate, but the thermal conductivity coefficient of coating $k$ is comparable to the thermal conductivity coefficient of the matrix.

The thermal conductivity resistance $R$ of composition SFC-1 and composition SFG-1 is four times higher than that of composition SFC-2 and composition SFG-2, which indicates much better heat insulating properties of these syntactic foams compositions.

\section{3 Infrared thermography}

Fig. 3 shows the results from the infrared thermography of the tested compositions of thin heatinsulation coatings. They fully correspond to the established thermal parameters of the tested compositions of thin coatings. Indicative of that are the established temperature differences $\Delta t$ of the temperatures on both sides of the experimental samples (Table 3).

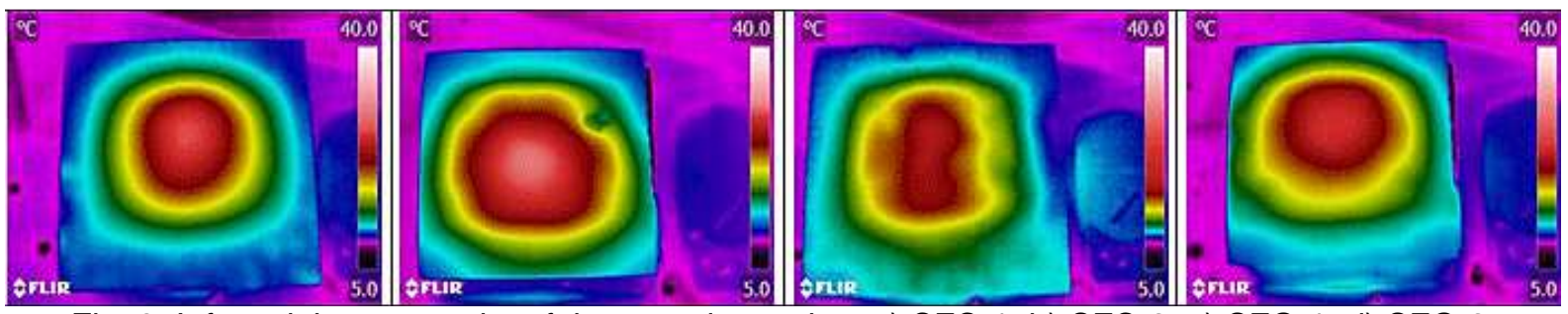

Fig. 3: Infrared thermography of the tested samples: a) SFC-1; b) SFC-2; c) SFG-1; d) SFG-2.

Table 3: Results of testing the samples with infrared camera.

\begin{tabular}{|c|c|c|c|}
\hline Composition & $\Delta t,{ }^{\circ} \mathrm{C}$ & $D_{\text {tmax }}, \mathrm{cm}$ & $D_{t=16,7}{ }^{\circ} \mathrm{C}, \mathrm{cm}$ \\
\hline SFC-1 & 10.4 & 8.5 & 10.4 \\
\hline SFC-2 & 6.8 & 10.8 & 16.8 \\
\hline SFG-1 & 7.8 & $4.3 \times 10$ & 11.8 \\
\hline SFG-2 & 7.0 & 9.3 & 12.4 \\
\hline
\end{tabular}

$D_{\text {tmax }}$ - the diameter of the temperature field with a maximum temperature (highlighted in red); $D_{t}$ - the diameter of the temperature field with a temperature of $16.7^{\circ} \mathrm{C}$, which is determined graphically

The infrared photographs are also indicative for the thermal diffusivity of the coatings. Thin coating SFC-2 has greater thermal diffusivity compared to coating SFC-1. The smallest thermal diffusivity belongs to coating SFG-2. The evidence of this are the data presented in Table 3 and in Fig. 4 - the diameter of the thermal field at one and the same temperature of $T=16.7^{\circ} \mathrm{C}$ is different for the individual coatings, where the greatest is for coating SFC-2 and the smallest the coating SFG-2.
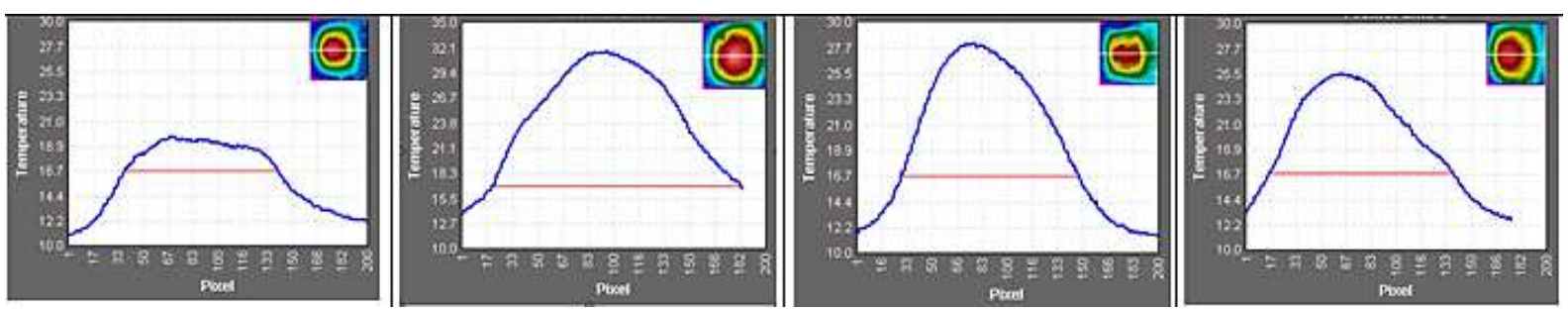

Fig. 4: Linear profile of temperature distribution of the tested samples, obtained by processing the infrared thermal images with FLIRResearchIR software.

\section{Conclusions}

Based on the results obtained from this study of thin coatings with different syntactic foams compositions, the following conclusions could be drawn: 
1. The best heat insulating properties belong to thin coatings with composition of $60 \mathrm{vol}$. $\%$ ceramic microspheres sized $1-40 \mu \mathrm{m}$ and to these with composition of 80 vol. \% glass hollow microspheres sized $9-25 \mu \mathrm{m}$. These two are also the compositions which have a compact structure and relatively smooth surface.

2. With the increase of the volume proportion of the ceramic microspheres from $60 \mathrm{vol}$. $\%$ to 80 vol. \%, the thermal conductivity coefficient increases 4 times.

3. As finest are the glass hollow microspheres, so compact is the structure of the composite, the lower is its density, and the lower is its thermal conductivity coefficient.

4. Larger-sized glass hollow microspheres enable lower thermal diffusivity of the thin coating.

At identical volume proportion of filler ( $80 \mathrm{vol}$. \%), the best heat insulating properties belong to the coating made of the finest glass microspheres.

The results, analyses and conclusions presented above give reason to state that thin heatinsulation coatings based on syntactic foam with ceramic or glass hollow microspheres are superior in terms of heat-conducting properties to a number of commonly used heat insulating materials and that they rival heat insulating materials, based on foamed plastics.

\section{References}

[1] ALLEN, M. - BAUMGARTNER, R. - FESMIRE, J. - AUGUSTYNOWICZ, S.: Advances in microsphere insulation systems. AIP Conference Proceedings Vol. 710, 2004, pp. 619 - 626.

[2] BOZSAKY, D.: Laboratory tests with liquid nano-ceramic thermal insulation coating. Procedia Engineering Vol. 123, 2015, pp. $68-75$.

[3] RYZHENKOV, A. - POGORELOV, S. - LOGINOVA, N. - BELYAEVA, E. - PLESTSHEVA, A.: Syntactic Foams Efficiency with the Use of Various Microspheres for Heat Supply Equipment and Pipelines Heat Insulation. Modern Applied Science, Vol. 9, № 4, 2015, pp. 319 - 327, doi:10.5539/mas.v9n4p319.

[4] LI, B. - YUAN, J. - AN, Z. - ZHANG, J.: Effect of microstructure and physical parameters of hollow glass microsphere on insulation performance. Materials Letters, Vol. 65, 2011, pp. 1992 - 1994.

[5] PARK, S.-J. - JIN, F.-L. - LEE, C.: Preparation and physical properties of hollow glass microspheres-reinforced epoxy matrix resins. Materials Science and Engineering A, Vol. 402, Iss. 1 - 2, 2005, pp. $335-340$.

[6] GENG, H. - LIU, J. - GUO, A. - REN, S. - XU, X. - LIU, S.: Fabrication of heat-resistant syntactic foams through binding hollow glass microspheres with phosphate adhesive. Materials Design, Vol. 95, 2016, pp. 32 - 38.

[7] RYZHENKOV, A. - LOGINOVA, N. - BELYAEVA, E. - LAPIN, Y. - PRISCHEPOV, A.: Review of binding agents in syntactic foams for heat-insulating structures in power industry facilities. Modern Applied Science, Vol. 9, 2015, pp. 96 - 105.

[8] GAO, J. - WANG, J. - XU, H. - WU, C.: Preparation and properties of hollow glass bead filled silicone rubber foams with low thermal conductivity. Materials Design, Vol. 46, 2013, pp. 491 - 496.

[9] MEE, S.: The Synthesis, Characterisation and Properties of Self-Assembled Hollow and Low Density Microspheres. PhD Thesis, University of Birmingham, 2011.

[10] HU, N. - DAI, J. - ZHU, Z. - HUANG, X. - WU, P.: Synthesis and characterization of hollow glassceramics microspheres. Composites Science and Technology, Vol. 72, 2012, pp. 528 - 532.

[11] YUNG, K. - ZHU, B. - YUE, T. - XIE, C.: Preparation and properties of hollow glass microspherefilled epoxy-matrix composites. Composites Science and Technology, Vol. 69, 2009, pp. 260 264.

[12] LIANG, J. - LI, F.: Measurement of thermal conductivity of hollow glass-bead-filled polypropylene composites. Polymer Testing, Vol. 25, 2006, pp. 527 - 531.

[13] ISO 22007-2:2015 Plastics - Determination of thermal conductivity and thermal diffusivity - Part 2: Transient plane heat source (Hot disk) method.

[14] ZLATEVA, P. - PETKOVA-SLIPETS R.: Comparative analysis of the results of measurements of the thermal conductivity of the insulating coating AKTERM. Proceedings of University of Ruse 2014, Vol. 53, book 1.2, 2014, pp. 47 - 51.

[15] http://www.farm.net/ mason/materials/thermal_conductivity.html, last accessed 2019/02/06. 